\title{
ANALISIS KINERJA EKONOMI WILAYAH PROVINSI SUMATERA BARAT
}

\author{
Syamsul Amar \\ Fakultas Ekonomi dan Bisnis, Universitas Negeri Padang \\ Email: syamsul amar2@yahoo.co.id
}

\begin{abstract}
Macro regional variables are engine in regional economy. Regional economy activity must be conducted by local resources and supported regulation from local government. Each regency and municipality in West Sumatera have leading sector economy. There are sevent regency/municipality led at primary sector, six regency/municipality led at secondary sector and and four regency/municipality led at tertiery sector. Leading sector economy as economic base created goods and service mobility through interregional trade efficienly and income multiplier effect as well as labour multiplier effect continuously. Therefore, needed government policy to accomodate the public interest bese on local potential
\end{abstract}

Keywords: Regional Economic, Leading Sector Economi, Government Policy.

\section{PENDAHULUAN}

D embangunan daerah merupakan bahagian integral dari pembangunan nasional maka sudah tentu keberhasilan pembangunan nasional akan ditentukan oleh keberhasilan pembangunan daerah. Aktivitas pembangunan pembangunan daerah terdiri dari pembangunan ekonomi, sosial, politik, budaya dan inftra struktur. Namun, karena keterbatasan sumberdaya ekonomi dalam setiap perekonomian, pada tahap awal proses pembangunan, pemerintah cenderung memokuskan terhadap pembangunan makro regional dan pembangunan bidang lain yang mendorong pembangunan bidang ekonomi.

Pembangunan makro regional suatu wilayah akan mempekuat kondisi perekonomian wilayah melalui peningkatan kinerja ekonomi sektoral. QE Journal | Vol.05 - No. 02 June 2016 - 102 
Dalam tataran teoritis dan normatif perekonomian wilayah dikonsepsikan sebagai faktor penggerak (prime mover) pertumbuhan ekonomi wilayah melalui effek pengganda (multiplier effect) pendapatan dan penyerapan tenaga kerja yang pada gilirannya akan meningkatkan kesejahteraan masyarakat. Namun dari sisi pandangan ekonomi politik, peningkatan kinerja perekonomian wilayah ditentukan juga oleh faktor non ekonomi ( institusi hukum dan politik). Menurut Philippe (1974) suatu kebijakan dianggap relatif tepat jika path of economic development berada dalam kerangka sistem yang didukung oleh potensi sumberdaya yang dimiliki. Distorsi yang semakin jauh dari jalur tersebut akan mengakibatkan rapuhnya fondasi ekonomi terhadap goncangan internal maupun eskternal.

Malapetaka yang dialami Indonesia selama ini akar permasalahannya terletak pada ketidaktepatan format kebijakan publik yang menyebabkan terjadinya public policy failure dan persoalan seperti ini akan dapat juga terjadi di daerah. Di beberapa negara bekembang, para pengambil kebijakan yakin bahwa paradigma pembangunan yang beronientasi pada pertumbuhan akan dapat menciptakan kesejahteraan public tanpa mengkaji sejauhmana asumsi paradigma tersebut dapat dipenuhi. World Development Report (1996) melaporkan bahwa mengadopsi growth model tanpa memenuhi asumsi, mengakibatkan terjadinya lima ekses yaitu; (1) jobless growth ( pertumbuhan tinggi-pengangguran tinggi), (2) rootless growth (pertumbuhan tinggi-social welfare rendah, (3) voiceless growth (pertumbuhan tinggi-partisipasi rendah), (4) roothless growth (pertumbuhan tinggi-budaya rendah) (5) futureless growth (pertumbuhan tinggi-lingkungan rusak). Oleh karena itu untuk meminimalkan dampak pertumbuhan ekonomi maka perencanaan pengembangan makro regional harus disesuaikan dengan kondisi internal dan faktor endowment suatu daerah serta kebutuhan publik agar kegiatan dapat meningkatkan kesejahteraan masyarakat secara keseluruhan.

Perekonomian wilayah adalah mesin penggerak pertumbuhan ekonomi wilayah melalui aktivitas produksi barang dan jasa yang dilaksanakan oleh rakyat bersama dengan pemerintah. Degan demikian perekonomian wilayah adalah perekonomian yang berbasis aktivitas ekonomi lokal yang lakukan oleh masyarakat yang landasi oleh potensi ekonomi yang dimiliki atas dukungan infra struktur ekonomi dan regulasi pemerintah. 
Perekonomian wilayah menghasilkan produk yang dikonsumsi oleh masyarakat dan lebihnya diekspor ke luar wilayah dan luar negeri melalalui perdagangan. Proses perdagangan antar wilayah dan internasioanl (interregional and intertational trade) akan menciptakan nilai tambah dalam memperkuat sistem perekonomian wilayah.

Tabel 1. Neraca Perdagangan Sumatera Barat Tahun 2010 - 2015 (000 USD)

\begin{tabular}{lccc}
\hline Tahun & Nilai Ekspor & Nilai Impor & Surplus \\
\hline 2010 & 408180,00 & 42574,00 & 165606,00 \\
2011 & 607849,00 & 34824,00 & 273025.00 \\
2012 & 777276,63 & 31132.82 & 346143,81 \\
2013 & 894955,75 & 15648,01 & 579307,74 \\
2014 & 1074134,18 & 36812,58 & 1037321,60 \\
2015 & 1607022,26 & 95861 & 1511160,27 \\
Pertumbuhan Rerata & $21,25 \%$ & $-13,87 \%$ & $34,12 \%$ \\
\hline
\end{tabular}

Sumber: Sumatera Barat Dalam Angka , 2008.

Pada periode 2010 - 2015 kinerja perekonomian wilayah Sumatera Barat relatif baik sebagaimana diperlihatkan oleh surplus perdagangan antar daerah dan internasional sebesar $21,25 \%$ dan di sisi lain arus impor cenderung menurun sebesar $-13,87 \%$ dan akibat dari kedua hal tersebut akan terjadi surplus perdagangan sebesar $34,12 \%$. Peningkatan kinerja perdagangan antar wilayah dan internasional ini di sebabkan oleh peningkatan produksi subsektor perkebunan, perikanan dan sektor pertambangan yang lima tahun terakhir di Sumatera Barat cukup berkembang dengan sangat signifikan. Trrwujudnya hal ini uga tidak terlepas dari dukungan pengembangan Pelabuhan Teluk Bayur sebagi pelabuhan niaga yang akhir-akhir ini telah memenahi dan melengkapi berbagai fasilitas dalam menunjang aktivitas lalu lintas barang antar daerah dan internasional.

\section{HASIL DAN PEMBAHASAN}

Studi ini bersifat expost facto dengan pendekatan studi regional, dengan menggunakan data skunder makro regional Sumatera Barat dalam kurun waktu 2011 - 2015. Untuk mengetahui sektor unggulan perekonomian wilayah dalam studi ini digunakan Model Ekonomi Regional yaitu Location Quotien. Kuosien lokasi (Location Quotien) merupakan salah satu alat analisis basis ekonomi (economic base) yang cukup efektif dalam 
perencanan pembangunan wilayah, Model ini bertujuan untuk mengetahui sektor-sektor ekonomi yang berperan sebagai basis ekonomi yang berfungsi sebagai penggerak (prime mover role) perekonomian suatu wilayah. Glasson (1974) mengemukakan bahwa ekonomi basis mempunyai peranan sebagai penggerak dalam dalam pertumbuhan ekonomi wilayah melalui effek pengganda. Semakin banyak aktivitas basis dalam suatu perekonomian wilayah akan meningkatnya arus ekspor barang dan jasa ke luar wilayah dan pada gilirannya hal tersebut akan menciptakan pertumbuhan ekonomi yang tinggi. Secara spesifik, ekonomi basis dapat diartikan sebagai wilayah yang telah berswasembada terhadap satu macam produk dalam memenuhi kebutuhan wilayahnya dan kelebihan produksinya dapat diekspor ke daerah lain. Sedangkan ekonomi non basis adalah wilayah yang belum dapat memenuhi kebutuhan produk di wilayahnya untuk itu mereka harus mengimpor dari luar wilayah.

Produk barang dan jasa yang dihasilkan pada suatu wilayah akan menciptakan pertumbuhan ekonomi melalui pembelanjaan terhadap barang dan jasa yang dihasilkan oleh perekomian wilayah. Menurut Tiebout (1972) pertumbuhan ekonomi suatu wilayah akan terjadi karena adanya effek pengganda dari pembelanjaan kembali atas pendapatan yang diperoleh melalui penjualan barang dan jasa yang dihasilkan oleh suatu wilayah. Angka pengganda tersebut disebut pengganda pendapatan (income multiplier). Di sisi lain peningkatan produksi barang dan jasa akan meningkatkan penyerapan tenaga kerja. Dampak dari proses produksi terhadap peyerapan tenaga kerja disebut dengan pengganda tenaga kerja (labour multiplier).

\section{Kinerja Makro Regional Sumatera Barat}

Kinerja makro regional merupakan gambaran aktivitas yang telah dilakukan oleh suatu daerah pada periode-priode sebelumnya. Propinsi Sumatera Barat berada di Bagian Tengah pulau Sumatera yang memiliki jumlah penduduk 6 juta jiwa. Pada periode 2011 - 2015 mermiliki kinerja makro regional yang cukup menggembirakan, meskipun masih ada beberapa indikator ekonomi yang belum begitu menggembirakan. Cukup baiknya kinerja ekonomi makro regional Sumatera Barat tidak dapat dipisahkan dengan faktor endowment yang dimiliki baik sumberdaya alam maupun sumberdaya manusia serta kebijakan yang telah dilakukan 
oleh pemerintah daerah. Secara akumulatif hal tersebut telah berdampak terhadap aktivitas ekonomi masyarakat sebagaimana ditunjukkan oleh beberapa indikator berikut:

1. Pada periode 2011 - 2015 sumbangan PDRB Sumatera Barat terhadap PDB telah mencapai 2,82 \% meskipun masih berada di bawah Sumatera Utara (6,3\%), DKI (17,8\%), Jabar (17,3\%), Jateng (10,5\%) Jatim (16,6\%). Riau (3,2\%) Sumsel (3,1\%), Riau (3,2\%) Sumsel (3,1\%), Namun telah berada di atas Kalimantan Timur (2,9\%) dan Sulawesi Selatan $(2,5 \%)$;

2. Pendapatan perkapita Sumatera Barat sebesar Rp. 22,41 juta dan secara nasional berada pada peringkat ke 14 . Hal ini memperlihatkan bahwa Sumatera Barat tergolong ke dalam daerah yang memiliki pendapatan perkapita rendah, namun memiliki pertumbuhan ekonomi cukup tinggi (rerata pertumbuhan $5,41 \%$ pertahun),. Hal ini dapat diartikan bahwa Sumatera Barat memiliki akseselarasi ekonomi yang relatif bagus tetapi kurang didukung potensi ekonomi yang ada.

3. Konsumsi mengalami pertumbuhan konsumsi cukup tinggi yaitu $10 \%$;

4. Struktur ekonomi masih didominasi oleh sektor primer terutama sektor pertanian dengan kontribusi terhadap PDRB sebesar 14,10\% dan secara relatif dari waktu ke waktu cenderung mengalami penurunan sebagai indikasi terjadnua transformasi ekonomi;

5. Realisasi penanaman Modal Dalam Negeri relatif masih rendah $(1,8 \%$ dari PMDN Nasional). Realisasi PMDN masih di bawah Sumatera Utara (2,6\%). Aceh (2,1\%), Riau (8,1\%), Jambi (2,4\%), Sumatera Selatan $(3 \%)$. Proporsi realisasi PMA masih sangat rendah hanya sebesar $0,4 \%$ dari PMA nasional;

6. Proporsi ekspor sebesar 2,1 \% dari total ekspor nasional;

7. Jumlah penduduk miskin relatif masih besar sebesar $9 \%$, dan Human Development Index 69,36 (ranking 9 dari 27 propinsi) lebih tinggi dari IPM nasional yaitu 68,90.

Selama periode 2011 - 2015 Provinasi Sumatera Barat memperlihatkan keinerja yang cukup baik meskipun masih ditemukan beberapa indikator makro regional yang masih belum begitu menggembiraka yang berdampak terhadap melambatnya proses percepatan pembangunan. Secara internal 
Propinsi Sumatera Barat memiliki potensi ekonomi yang cukup baik karena didukung oleh pemilikan sumberdaya alam dan sumberdaya manusia yang cukup memadai. Luas daratan Sumatera Barat $42.297 \mathrm{~km}$ persegi $(2,17 \%$ dari luas daratan Indonesia), lautan $57.880 \mathrm{~km}$ persegi, rerata tahun pendidikan 8,57 tahun dan usia harapan hidup (life expectation rate) 69,50 tahun namun angka tersebut lebih tinggi dari pendidikan ratarata dan sia harapan hidup nasional. Kondisi tersebut merupakan modal dasar bagi Sumatera untuk meningkatkan kinerja perekonomian wilayahnya untuk meningkatkan kesejahteraan masyarakatnya.

Tabel 2. Profil Perekonomian Wilayah Provinsi Sumatera Barat Tahun $2010-2015$

\begin{tabular}{|l|c|c|c|c|}
\hline Sektor Ekonomi & $\begin{array}{c}\text { Alokasi Investasi } \\
(\%)\end{array}$ & ICOR & LQ & $\begin{array}{c}\text { Pertumbuhan } \\
(\%)\end{array}$ \\
\hline Pertanian & 32,28 & 4,36 & 3,05 & 3,76 \\
Pertambangan & 15,16 & 4,93 & 2,05 & 2,03 \\
Industri & 23,03 & 4,24 & 1,17 & 3,92 \\
Listrik & 4,17 & 6,05 & 0,87 & 17,95 \\
Bangunan & 7,15 & 5.37 & 0,97 & 0,19 \\
Perdagangan & 4,20 & 4,36 & 2,45 & 3,94 \\
Angkutan dan Komunikasi & 3,48 & 5,02 & 2,38 & 5,10 \\
Keuangan, persewaan & 7,06 & 3,34 & 0,58 & 0,64 \\
Jasa-Jasa & 2,476 & 4,20 & 0,87 & 3,89 \\
\hline Total/rata-rata & 100,00 & 4,65 & 1,60 & 4,60 \\
\hline
\end{tabular}

Sumber : Data Sekunder Makro Regoinal Sumbar diolah

Secara regional tingkat pelaksanaan investasi di Sumatera cukup effisien sebagaimana ditunjukkan oleh nilai rerata increasing capital out ratio (ICOR) sebesar 4,76 dan lebih baik jika dibandingkan dengan ICOR nasional yaitu 5,50. Namun yang menarik adalah sektor listrik memiliki ICOR yang paling tinggi yaitu 6,05, terjadinya kondisi tersebut tidak terlepas dari investasi yang sangat besar dengan jangka waktu pengembalian (payback) yang sangat lama namun dalam lima tahun terakhir pertumbuhan sektor ini adalah paling tinggi yaitu 17,95\% karena ada beberapa pembangunan pembangkit baru yang berasal dari inevestasi asing untuk memenuhi kebutuhan listrik pada tiga provinsi yaitu Sumatera Barat, Riau dan Jambi. Berbeda kondisinya dengan sektor keuangan dan persewaan dengan ICOR 3,34 dan jasa 4,20. Alokasi invstasi yang paling besar terdapat pada sektor pertanian di susul oleh industri dan pertambangan dan ketiga kegiatan ekonomi tersebut cukup effisien dan masing-masing sebagai sektor unggulan perekonomian (leading sectors QE Journal | Vol.05 - No. 02 June 2016 - 107 
economy) Sumatera Barat. Di sisi lain yang menarik adalah sektor perdagangan dan transportasi dengan alokasi investasi yang realatif kecil namun tetap menjadi unggulan perekonomian wilayah Sumatera Barat. Hal ini membuktikan bahwa telah sejak lama masyarakat Sumatera Barat (Minangkabau ) secara kultural terkenal dengan aktivitas pergadangannya sebabagai basis ekonomi rakyat di di daerah ini. Kondisi ini erat kaitannya dengan kelancaran sarana dan prasarana transportasi yang yang relatif baik di Sumatera Barat yang juga menjadi sektor unggulan di daerah ini . Namun, penaman modal swasta nasional (PMDN maupun PMA) di Sumatera Barat relatif masih kecil jika dibandingkan dengan daerahdaerah lain di Indonesia hal ini juga tidak terlepas dengan kekuatiran investor untuk menanamkan modal di daerah ini karena akibat pencitaan derah Sumatera barat sebagai daerah rawan gempa dan tsunami . Suatu fenomena yang cukup memprihatinkan dalam lima tahun terakhir beberapa perusahaan swasta dan BUMN telah memindah kantor wilayahnya ke Provinsi Riau sebagai akibat kekuatiran mereka terhadap ancaman gempa dan tsunami. Realisasi investasi periode 2011 - 2015 hanya sebesar $0,48 \%$ dan sektor publik $0,68 \%$ dari total investasi nasional, namun peningkatannya cukup menggembirakan yaitu sebesar 4,38\% karena adanya nvestasi baru di sektor listrik (pembangunan pembangkit) dan pembangunan hotel-hotel baru dan juga sektor subsektor kelautan sementara di bidang industri dan pengelohan tidak mengalami peningkatan yang bermakna.

Dari dua belas kabupaten dan kota yang ditetapkan sebagai objek studi, masing-masing kabupaten/kota memiliki keunggulan sesuai dengan potensi ekonomi wilayahnya masing -masing. Sebanyak delapan di antara kabupaten dan kota mememiliki keunggulan pada sektor primer. Kabupaten/kota tersebut adalah Kabupaten Tanah Datar, Kabupaten Agam, Kabupaten 50 Kota, Kabupaten Pasaman, Kabupaten Sijunjung, Kabupaten Solok, Kabupaten Sijunjung dan Kota Padang Panjang. Dari delapan kabupaten/ kota yang memiliki keunggulan pada sektor primer hanya sebanyak tiga kabupaten dan satu kota yang memiliki keunggulan yang kuat. Kabupaten tersebut yaitu: Kabupaten Agam, Kabupaten Sijunjung dan Kabupaten Sijunjung dan Kota Solok. Ketiga kabupaten yang memiliki keunggulan pada sektor primer tersebut secara geografis adalah kabupaten yang memiliki lahan pertanian yang luas. Kabupaten Agam dan Solok. Adalah wilayah sebagai sentra pertanian tanaman 
pangan dan holtikultura dan Kabupaten Pasaman dan Kabupaten Sijunjung adalah sebagai sentra perkebunan sawit dan karet baik milik perusahaan maupun perkebunan rakyat.

Pembangunan daerah merupakan bahagian integral dari pembangunan nasional maka sudah tentu keberhasilan pembangunan nasional akan ditentukan oleh keberhasilan pembangunan daerah. Aktivitas pembangunan pembangunan daerah terdiri dari pembangunan ekonomi, sosial, politik, budaya dan inftra struktur. Namun, karena keterbatasan sumberdaya ekonomi dalam setiap perekonomian, pada tahap awal proses pembangunan, pemerintah cenderung memokuskan terhadap pembangunan makro regional dan pembangunan bidang lain yang mendorong pembangunan bidang ekonomi .

Pembangunan makro regional suatu wilayah akan mempekuat kondisi perekonomian wilayah melalui peningkatan kinerja ekonomi sektoral. Dalam tataran teoritis dan normatif perekonomian wilayah dikonsepsikan sebagai faktor penggerak (prime mover) pertumbuhan ekonomi wilayah melalui effek pengganda (multiplier effect) pendapatan dan penyerapan tenaga kerja yang pada gilirannya akan meningkatkan kesejahteraan masyarakat. Namun dari sisi pandangan ekonomi politik, peningkatan kinerja perekonomian wilayah ditentukan juga oleh faktor non ekonomi ( institusi hukum dan politik). Menurut Philippe (1974) suatu kebijakan dianggap relatif tepat jika path of economic development berada dalam kerangka sistem yang didukung oleh potensi sumberdaya yang dimiliki. Distorsi yang semakin jauh dari jalur tersebut akan mengakibatkan rapuhnya fondasi ekonomi terhadap goncangan internal maupun eskternal. World Development Report (1996) melaporkan bahwa mengadopsi growth model tanpa memenuhi asumsi, mengakibatkan terjadinya lima ekses yaitu; (1) jobless growth (pertumbuhan tinggi-pengangguran tinggi), (2) rootless growth (pertumbuhan tinggi-social welfare rendah, (3) voiceless growth (pertumbuhan tinggi-partisipasi rendah), (4) roothless growth (pertumbuhan tinggi-budaya rendah) (5) futureless growth (pertumbuhan tinggi-lingkungan rusak). Oleh karena itu untuk meminimalkan dampak pertumbuhan ekonomi maka perencanaan pengembangan makro regional harus disesuaikan dengan kondisi internal dan faktor endowment suatu daerah serta kebutuhan publik agar kegiatan dapat meningkatkan kesejahteraan masyarakat secara keseluruhan. 
Perekonomian wilayah menghasilkan produk yang dikonsumsi oleh masyarakat dan lebihnya diekspor ke luar wilayah dan luar negeri melalalui perdagangan. Proses perdagangan antar wilayah dan internasioanl (interregional and intertational trade) akan menciptakan nilai tambah dalam memperkuat sistem perekonomian wilayah.

Tabel 3. Neraca Perdagangan Sumatera Barat Tahun 2010 - 2015 (000 USD)

\begin{tabular}{lccc}
\hline Tahun & Nilai Ekspor & Nilai Impor & Surplus \\
\hline 2010 & 408180,00 & 42574,00 & 165606,00 \\
2011 & 607849,00 & 34824,00 & 273025.00 \\
2012 & 777276,63 & 31132.82 & 346143,81 \\
2013 & 894955,75 & 15648,01 & 579307,74 \\
2014 & 1074134,18 & 36812,58 & 1037321,60 \\
2015 & 1607022,26 & 95861 & 1511160,27 \\
\hline Pertumbuhan Rerata & $21,25 \%$ & $-13,87 \%$ & $34,12 \%$ \\
\hline
\end{tabular}

Sumber: Sumatera Barat Dalam Angka , 2008.

Pada periode 2010 - 2015 kinerja perekonomian wilayah Sumatera Barat relatif baik sebagaimana diperlihatkan oleh surplus perdagangan antar daerah dan internasional sebesar $21,25 \%$ dan di sisi lain arus impor cenderung menurun sebesar $-13,87 \%$ dan akibat dari kedua hal tersebut akan terjadi surplus perdagangan sebesar $34,12 \%$. Peningkatan kinerja perdagangan antar wilayah dan internasional ini di sebabkan oleh peningkatan produksi subsektor perkebunan, perikanan dan sektor pertambangan yang lima tahun terakhir di Sumatera Barat cukup berkembang dengan sangat signifikan. Trrwujudnya hal ini uga tidak terlepas dari dukungan pengembangan Pelabuhan Teluk Bayur sebagi pelabuhan niaga yang akhir-akhir ini telah memenahi dan melengkapi berbagai fasilitas dalam menunjang aktivitas lalu lintas barang antar daerah dan internasional.

Sebanyak lima kabupaten dan kota yaitu Kabupaten Pasaman, Kabupaten 50 kota, Kota Padang, Kota Bukitting, Kota Padang Panjang dan Kota Payakumbuh sebagai daerah yang memiliki keunggulan pada sektor ekonomi sekunder yang teridir sektor industri, sektor perdagangan dan dan sektor konstruksi. Dari limat kabupaten/kota tersebut sebanyak empat kotah yang memiliki leading sektor yang kuat (LQ jauh lebih besar dari 1).

Kota-kota tersebut yaitu: Kota Padang, Kota Bukitting, Kota Padang Panjang dan Kota Payakumbuh. Keempat kota tersebut adalah sebagai 
sentra bisnis yang cukup terkenal di Sumatera Barat yang dikunjungi oleh banyak masyarakat baik dari kabupaten/kota lain di Sumatera Barat maupun dari luar propinsi dan juga mancanegara. Khususnya kota Bukuittingnya kota wisata yang sangat terkenal di Sumatera Barat yang sangat banyak dikunjungi oleh masyarakat dari luar propinsi dan keunjungan dari masyarakat negara tetangga terutama dari Malaysia dan Brunai Darussalam. Keberadaan keempat kabupaten/kota tersebut sebagai sentra bisnis merupakan bagian tidak terpisahkan dengan pengembangan pada sektor industri sebagai penghasil produk dan transportasi dalam memfasilitasi mobilitas masyarakat.

Di sisi lain Kabupaten Pasaman adalah kabupaten sebagai sentra perkebunan sawit dan industri pengolahan $\mathrm{CPO}$ terbesar di Sumatera Barat dan Kabupaten 50 kota adalah sebagai sentra industri pengolahan gambir sebagai salah satu komoditi ekspor Sumatera Barat. Sebagai sentra industri $\mathrm{CPO}$ dan gambir terbesar di Sumatera Barat merupakan bagian yang tidak terpisahkan dengan pengembangan sektor transportasi dan komunikasi serta pembangunan infrasruktur yang saling mengkait dan menunjang. Sedangkan pada sektor tertier yang terdiri dari sektor keuangan dan persewaan serta jasa terdapat sebanyak empat kabupaten/kota yang memiliki keungulan pada sektor ini. Kabupaten/kota tersebut antara lain: Tanah Datar, Padang, Bukittingi dan Payakumbuh. Keempat daerah tersebut merupakan daerah sentra wisata dan yang memiliki objek wisata yang cukup terkenal di Sumatera Barat. Selama lima tahun terkahir jumlah kunjungan wisata ke Sumatera Barat mengalami peningkatan yang cukup signifikan yaitu sebesar $12,13 \%$ baik sebagai wisata belanja, kuliner dan wisata alam dan budaya, khusus Kota mengalami peningkatan sangat signifikan dalam pembangunan Padang sarana wisata seperti hotel dan pembenahan objek wisata pantai yang berdampat signifikan terhadap jumlah kunjungan.

Keberadaan basis ekonomi sebagai keunggulan komparatif (comparative adventages ) wilayah akan memiliki dampak signifikan terhadap penciptaan pendapatan wilayah dan kesempatan kerja wilayah melalui efek multiplier pendapatan dan tenaga kerja. Multiplier pendapatan (income multiplier) jangka panjang ekonomi basis di Sumatera Barat, pada periode 2011 - 2015 rata-rata sebesar 14,48 dan pengganda tenaga kerja (labour multiplier) sebesar 14,76. Hal ini dapat diartinya jika produksi ekonomi basis 
mengalami peningkatan sebesar Rp.1 milyar akan memiliki effek terhadap peningktan pendapatan wilayah sebesar Rp. 14,48 miyar dan terhadap penyerapan tenaga kerja sebnyak 14,79 orang.

Tabel 4. Rata-Rata Indeks LQ UKM dan Besar, Pertanian dan Jasa Kabupaten dan Kota di Sumatera Barat Tahun 2011-2015

\begin{tabular}{|c|c|c|c|c|c|}
\hline \multicolumn{3}{|r|}{ Daerah } & \multirow[t]{2}{*}{1} & \multirow[t]{2}{*}{ II } & \multirow[t]{2}{*}{ III } \\
\hline$A$ & \multicolumn{2}{|c|}{ Kabupaten } & & & \\
\hline & 1 & Tanah Datar & 0,95 & 0.21 & 1,23 \\
\hline & 2 & Padang Pariaman & 0.91 & 0.67 & 0,98 \\
\hline & 3 & Agam & 3.19 & 0.70 & 0,78 \\
\hline & 4 & 50 Kota & 3.34 & 1,28 & $0, .28$ \\
\hline & 5 & Pasaman & 3.02 & 1.16 & 0.55 \\
\hline & 6 & Sijunjung & 3,05 & 0,79 & 0,75 \\
\hline \multirow[t]{8}{*}{ B } & \multicolumn{5}{|c|}{ Kodya } \\
\hline & 1 & Padang & 0.56 & 2.85 & 3.26 \\
\hline & 2 & Solok & 3.65 & 0.62 & 0.55 \\
\hline & 3 & Sawah Lunto & 0,76 & 0.31 & 0,96 \\
\hline & 4 & Padang Panjang & 1.64 & 2.39 & 0,86 \\
\hline & 5 & Bukittinggi & 0.90 & 2.98 & 2.63 \\
\hline & \multirow[t]{2}{*}{6} & Payakumbuh & 0.60 & 3.45 & 2.43 \\
\hline & & Rerata & 1.88 & 1,45 & 1,27 \\
\hline
\end{tabular}

Sumber: Data diolah dari hasil penelitian, 20015

I adalah sektor primer; II adalah sektor sekunder; III adalah sektor tersier

Terjadinya multipler pendapatan dan tenaga kerja disebabkan terjadinya peningkatan konsumsi masyarakat sebagai akibat meningkatkan pendapatan yang menunut terjadinya reinvestasi selanjutnya. Kegiatan reinvestasi akan meningkatkan kesempatan kerja dan secara langsung akan meningkatan pendapatan wilayah. Cukup tingginya pengganda tenaga kerja di Sumatera barat disebabkan pada umumnya kegiatan ekonomi basis (keunggulan) masih bersifat padat modal (labour intensive) namun hal ini akan memiliki dampak postif terhadap penyerapan teaga kerja di daerah ini,

Pangsa relatif ekonomi basis di Sumatera Barat sebesar 10,74 dan pangsa ini lebih tinggi ketimbang Indonesia $(8,82)$ dan indeks surplus relatif 1,92, sedangkan indeks absulut sebesar 350, 189 milyar. Surplus absulut berasal dari selisih antara total produksi dengan total konsumsi di Sumatera Barat dan surplus tersebut diekspor ke luar daerah. Di sisi lain ekonomi basis sebagai keunggulan komparatif dan kompetitif wilayah sebagai kekuatan

QE Journal | Vol.05 - No. 02 June 2016 - 112 
wilayah dalam mengembangkan dirinya atas dasar potensi yang dimilikinya tanpa bersaing dengan wilayah lain. Dengan pengembangan ekonomi basis akan menndorong terjadinya mobilitas barang dan jasa antar wilayah secara lebih effisien dalam mencipatakan nilai tambah yang lebih tinggi bagi perekonomia wilayah. .

Tabel 5. Pengganda Pendapatan, Tenaga Kerja, Indeks Surplus dan Relatif Usaha Kecil dan Menengah di Sumatera Barat

\begin{tabular}{|c|c|c|c|c|}
\hline Tahun & MY & $\overline{M L}$ & ISR & $\begin{array}{l}\text { ISA } \\
\text { (Rp. Jutaan) }\end{array}$ \\
\hline 2011 & & 11,02 & 14,72 & \\
\hline 2012 & & 10,91 & 15,07 & \\
\hline 2013 & & 10,60 & 14,74 & \\
\hline 2014 & & 12,36 & 14,48 & \\
\hline 2015 & & 12,53 & 14,82 & \\
\hline rerata & & 11,48 & 14,76 & 350,189 \\
\hline
\end{tabular}

Sumber : Data diolah, Hasil Penelitian 2015

\section{SIMPULAN DAN SARAN}

Persoalan perekonomian wilayah berkaitan dengan pengembangan ekonomi makro regional, dengan demikian perencanaan pengembangan ekonomi makro regional harus dilakukan melalui analisis komprehensif agar tidak menimbulkan eksternalitas disekonomis yang merugikan masyarakat. Oleh karena itu daerah harus mampu mengembangkan variabel-variabel makro regional secara optimal melalui aktivitas ekonomi masyarakat yang didukung oleh potensi ekonomi wilayah dan bersama dengan kebijakan pemerintah. Setiap kebijakan yang diambil seharusnya berorientasi kepada pencapaian kesejahteraan masyarakat (human well being) sebagai tujuan hakiki dari pembangunan.

Pengembangan ekonomi wilayah Sumatera Barat telah berjalan sesuai dengan potensi sumberdaya alam dan manusia yang dimilikinya, hal ini secara eksplisit diperlihatkan oleh keunggulan masing-masing kabupaten/kota. Sebanyak tujuh kabupaten/kota di Sumatera Barat memiliki keunggulan pada sektor ekonomi primer, sebanyak enam di antaranya memiliki keunggulan pada sektor ekonomi skunder dan sebanyak empat kabupate/kota memiliki keunggulan pada sektor ekonomi tertier. Perwujudan ekonomi basis di Sumatera Barat telah mendorong mobilitas barang dan jasa melaui perdagangan antar wilayah secara secara 
effisien sebagaimana ditunjukan oleh indeks surplus relatif 1,92 dan indeks absulut sebesar 350,189 milyar serta memiliki dampak pengganda terhadap peningkatan pendapatan wilayah dan penyerapan tenaga kerja wilayah secara bermakna.

\section{DAFTAR PUSTAKA}

Barron, David P (2001). Business it Environment, New York : McGraw Hill.

Buchanan, James (1989). Public Choice and Social Welfare,New York: McMillian Hill.

Basri, Faisal H (1995). Perekonomian Indonesia Menjelang Abad XXI.,

Jakarta: Penerbit Airlangga.

Schitter, Philippe (1974). Public Policy Making, New York: McGraw Hill Book Company.

Sudarsono, Juwono (1995). Politik Ekonomi dan Strategi, Jakarta: Gremedia Pustaka Utama.

Tambunan, Tulus T.H. (2001). Transformasi Ekonomi di Indonesia, Jakarta: Salemba Empat. 